\title{
Comparison of a Direct-Connect and Freejet Dual-Mode Scramjet
}

\author{
A Thesis presented to \\ the faculty of the School of Engineering and Applied Science \\ University of Virginia \\ In partial fulfillment \\ of the requirements for the degree \\ Master of Science
}

by

Thomas B. Steva

December 2013 


\section{Approval Sheet}

The thesis is submitted in partial fulfillment of the

requirements for the degree of

Master of Science

T. Steva

Author

The thesis has been read and approved by the examining committee:

$\frac{\text { C. Goyne }}{\text { Thesis Advisor }}$

J. McDaniel

E. Loth

Accepted for the School of Engineering and Applied Science:

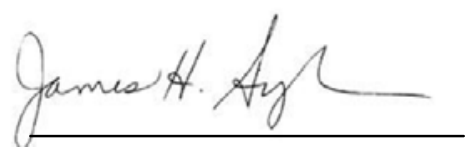

Dean, School of Engineering and

Applied Science

December 2013 


\begin{abstract}
Testing of identical dual-mode scramjet flowpath geometries in the freejet and direct-connect configurations were conducted in the ATK GASL Test Bay IV and the University of Virginia Supersonic Combustion facilities, respectively. These tests enabled a comparison study between the two configurations which was directed towards the determination of the effects of inlet distortion and back pressure on the performance and operability of a dual-mode scramjet. Bulk flow conditions were matched between the two facilities at the isolator entrance plane to simulate Mach 4.8 flight, and a series of metrics were established to quantify the similarities and differences of the two configurations. The effects of flowpath back pressure in the direct-connect case were seen to be isolated to regions close to the exhaust. Performance of the scramjet was generally well matched between the two configurations. An approximate $10 \%$ decrease in combustor pressure rise and consequently integrated pressure force were observed in the freejet configuration, however shock train length was unaffected. In terms of operability, it was determined that the decreased pressure rise led to a change in mode transition from an equivalence ratio of $\sim 0.5$ in the direct-connect to $\sim 0.7$ in the freejet configuration. In addition, ignition difficulties were experienced in the freejet tests which were not encountered in those of direct-connect, leading to a limited set of equivalence ratios available for comparison. Though somewhat limited in scope, this work represents the first detailed comparison in the literature of an identical direct-connect and freejet dualmode scramjet. This provides important insight into the effects of inlet distortion and back pressure on performance and operability, the understanding of which are necessary for the effective extrapolation of ground test data to flight.
\end{abstract}




\section{Nomenclature}

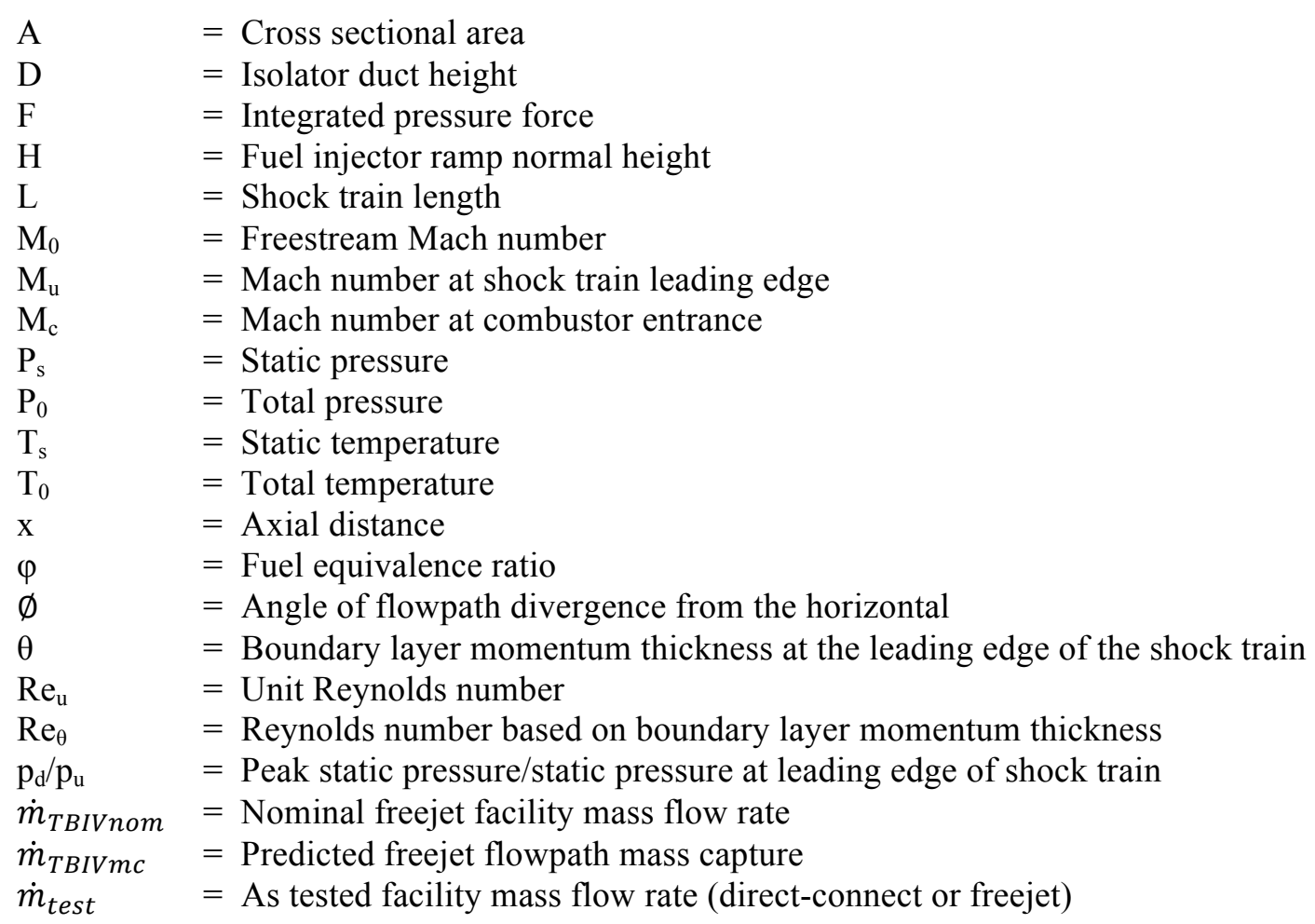

\section{I) Introduction}

As hypersonic air-breathing propulsion development progresses towards high speed aircraft and space access applications it will become increasingly necessary to conduct full scale scramjet flowpath ground testing in the direct-connect type configuration. In a direct-connect test the engine consumes $100 \%$ of the facility airflow delivered through the ground test facility nozzle with the target test conditions typically being set at the isolator inlet throat. However, in a freejet test, the engine with relevant vehicle inlet geometry is placed in a flow field that fully engulfs the test article. While the benefits of being able to accurately reproduce forebody and inlet distortion effects in the freejet configuration are apparent, the practical considerations of operating such an experiment become staggering as the simulated flight Mach number is increased. For a freejet simulation of a vehicle along a constant dynamic pressure trajectory of $48 \mathrm{kPa}(1000 \mathrm{psf})$, the required facility total pressure at Mach numbers of 5,10 , and 15 are on the order of 1,10 , and $100 \mathrm{MPa}$, respectively. Estimates of the total 
power required to run a continuous flow facility at the stagnation pressures and temperatures required to simulate flight for the same set of Mach numbers, (at a mass flow rate of around $50 \mathrm{~kg} / \mathrm{s}$ ), provide values of approximately 50,200, and $500 \mathrm{MW}$, respectively [1].For perspective, the power output of a typical industrial scale nuclear reactor is within the $500-1000 \mathrm{MW}$ range [2]. When considering these estimates it's also important to note that they do not include any thermodynamic losses, and thus actual power requirements would be even higher. While shock-expansion tubes, such as the NASA HyPulse facility at ATK GASL, are capable of producing the required freestream total pressures and total enthalpies for Mach numbers as high 20, they are limited to test times on the order of milliseconds [3]. Whereas test times of this order are generally seen to be adequate for the determination of performance characteristics, they are not sufficient for determination of operability or durability characteristics of the engine [4]. Thus, there remains a benefit to longer duration testing.

In contrast to freejet, when testing in the direct-connect configuration the required total pressure can be decreased by as much as a factor of six if the facility nozzle exit is placed at the simulated combustor entrance [1], or in the case of a dual mode scramjet, at the entrance to the isolator. This is due to the need only to replicate the conditions entering the flowpath, which consist of a lower total pressure due the forebody and inlet compression system. Further, given that the power required to operate a continuous flow facility for a specified Mach number is directly proportional to the mass flow rate, the facility construction and operational costs can be significantly reduced due to the need only to reproduce the engine internal mass flow rate. While the overall reduction in the minimum power requirement is dependent on a number of factors specific to a given test and vehicle inlet geometry, it is instructive to consider the differences in facility mass flow for the tests particular to this study. Here the freejet flowpath mass capture was approximately $2 \%$ that of the facility mass flow rate. Since minimum power scales directly with this property, this is a nearly 50 fold decrease to run the same test in the directconnect configuration.

Many aerodynamic systems can be adequately simulated with subscale wind tunnel models by matching any of a number of dimensionless parameters, for example Reynolds number. However, this is 
not necessarily the case for supersonic combustion applications [4]. In supersonic combustion the challenges of correctly scaling wind tunnel experiments become intensified by the presence of nonequilibrium chemical reactions. If the characteristic time of the combustion reaction is on the same order as that of the residence time of the flow, then a scaled model of the engine operating at the same freestream conditions and fuel equivalence ratio will not necessarily produce the same combustion characteristics. This serves to further illustrate the potential advantages of direct-connect testing in that the need to reproduce only the internal flowpath mass flow rate allows for larger full scale engine geometries to be tested.

Empirical validation of ground test techniques is a persistent requirement in the field of hypersonics. Given the highly integrated airframe-engine nature of scramjets, testing in the direct-connect configuration presents its own set of validation questions. Of particular concern is the appropriate matching of conditions at the entrance to the isolator. In flight and freejet test conditions oblique shocks emanating from the cowl leading edge and mold-line contour variations combine and interact with the growing forebody boundary layer. This interaction can even induce a local separation at the isolator entrance, which in turn generates an additional oblique shock that propagates through the flowpath and further increases the boundary layer thickness along the wall in which the shock is impinging. It has been shown [5] that a doubling of the boundary layer thickness can lead to an $\sim 5 \%$ decrease in the maximum operability of the inlet contraction ratio, or maximum sustainable back pressure before unstart. Further, if the pre-combustion shock train is near the inlet and in close proximity to the compression and expansion waves, interaction between these features can lead to a strengthening of the compression system and an overall decrease in the length of the shock train [6]. Interestingly, this was seen to increase the maximum sustainable back-pressure, which is opposed to the above mentioned effects of the increased boundary layer thickness alone. Ultimately however, in the direct-connect configuration where the facility nozzle exhausts directly into the isolator, the flow contains none of these distortions and non-uniformities. This is the significant difference between direct-connect and freejet test configurations. Therefore, understanding how engine performance and operability characteristics are affected by this difference is 
critical for the effective use of direct-connect test results in the development of future scramjet engines. It must be kept in mind, however, that direct-connect facilities may introduce their own flow nonuniformities. While more subtle than inlet distortion, these facility dependent characteristics could have their own effects on performance and operation that should be considered.

In addition to the effects of inlet distortion, another difference which can arise between testing configurations is that of back pressure, or the pressure at the exit of the engine expansion/nozzle section. In a typical flight scenario the static pressure at the exit is influenced by the operating altitude along with the vehicle geometry and its subsequent distortion of the flow field. For hypersonic applications this influence can be very significant due to the numerous compressions emanating from the vehicle and engine leading edges. This effect can be replicated in freejet testing if the relevant section of the vehicle is incorporated into the test article, and the test chamber exhausts to a lower pressure environment, such as a vacuum chamber. Similarly, the back pressure in a direct-connect configuration can also be set to that expected in flight with the use of a controllable vacuum system at the engine exit. Implementation of these devices is not always feasible however, and can often be cost prohibitive due to model, facility, and flow rate complexities. Due to these limitations a range of back pressures can exist from facility to facility, and often even over time within the same run. As is the case for all supersonic flows, if the pressure at the exit is sufficiently higher in a scramjet engine than that of the flow, a shock system will set up inside of the nozzle. Conversely, if the back pressure is lower than that of the exhaust, the flow will continue to expand all the way to the exit, without the formation of a shock train. It is therefore important to understand what effects varying back pressure, and the subsequently varying exit configurations, will have on the scramjet combustor.

A logical way to quantify the effects of inlet distortion and back pressure empirically is to test the same geometry scramjet in both freejet and direct-connect configurations where conditions at the isolator inlet are matched as closely as possible, and conditions at the engine exit are varied from facility to facility and test to test. These were, in part, the objectives of the Short Duration Propulsion Test and Evaluation (SDPTE) program [7], under the auspices of which the data presented in this paper were 
collected. While scramjet development programs have a long history of using both direct-connect and freejet testing to validate engine geometry $[8,9,10]$, often the data is only referenced in a compendium of the test campaign, or if comparisons are presented they are generally very brief. In [11] a comparison study was performed of tests conducted on an identical flowpath in a JAXA direct-connect blowdown facility and the University of Queensland T4 impulse freejet facility. Although the scramjet flowpath performed in a similar manner in the two facilities, the freejet flowpath did not use a traditional scramjet inlet. Rather, a convergent section was used in the freejet configuration to create a normal shock, behind which a diverging nozzle was used to match the conditions to the direct-connect facility. Thus, by adopting this approach, the effect of inlet distortion on the scramjet performance and operation could not be established.

An alternative technique for studying the effects of inlet distortion is that being developed by Gruber et al. [12], whereby a piece of hardware, attached between the isolator and nozzle in a directconnect test, is used to generate the expected expansion and compression waves emanating from a freejet inlet. The advantage of this approach is that by performing tests with and without this distortion generator, the effects of distortion can be effectively isolated. In addition, the flowpath mass rate is also known with much greater certainty than in a traditional freejet test. Currently, the generated distortions are limited to two dimensions, and the increased boundary layer growth along the vehicle forebody is not simulated. While experimental results are still forthcoming, ultimately a comparison of results obtained with the use of this technique and those obtained from a study conducted with a real inlet where all distortions are generated would be instructive; and the two techniques complimentary.

While some technology demonstration programs have employed the use of both freejet and direct-connect tests $[8,9,10]$, and studies have been undertaken to examine the effects of inlet distortion on the inlet and isolator operability using artificially pressured conditions $[5,6]$, a need for a detailed scientific comparison with actual inlet distortion and scramjet combustion remains. Therefore, the first objective of this paper is to provide such a comparison between the performance and operability of a direct-connect and freejet scramjet flowpath. This will be achieved through quantification of the 
similarities and differences of axial pressure distributions obtained from experimental testing of a dualmode scramjet. The second objective is to provide insight into the relevance of previously published results obtained in the direct-connect facility of the current study $[13,14,15,16]$. Of particular concern here is to confirm the direct-connect facility can capture many of the relevant flow physics of a freejet test. To the authors' knowledge, this study presents the first results of an identical dual-mode scramjet flowpath that has been tested in direct-connect mode and in freejet mode with a flight-like inlet. While the findings of the study will be limited to a particular flowpath geometry and the specific conditions tested, the effects of inlet distortion and flowpath backpressure observed will aid in the extrapolation of past and future direct-connect studies to freejet and flight. The present study will also add important insight into the potential benefits and limitations of the two different ground test configurations.

To serve these objectives this paper starts by first describing the set of experiments which will allow for the comparison of the freejet and direct-connect configurations. Attention is paid to the characteristics of interest for each facility and what conditions were matched so as to provide as close of a comparison as possible. Next, a set of data driven metrics are established which are used to quantify the comparison between the two configurations. The results section first presents the data and general trends from the direct-connect test, followed by an examination of the effects of varying back pressure to frame the validity of the comparison. After this, the results from the freejet testing are presented and discussed. Finally, the results from the two configurations are compared qualitatively as well as quantitatively with the use of mentioned metrics. A discussion exploring the potential reasons for some of the observed similarities and differences ensues.

\section{II) Experimental Technique}

As mentioned above, the work presented here was conducted as part of the SDPTE program. That program involved the ground testing of two different engine geometries, referred to as Flowpath A and Flowpath B, which were designed for a possible flight experiment [7]. The geometries for the two 
flowpaths were based on a dual mode scramjet (DMSJ) which has been the subject of extensive long duration testing in the direct-connect configuration using the University of Virginia Supersonic Combustion Facility (UVaSCF). In order to adapt the direct-connect geometry to flight and freejet test articles, a vehicle forebody and inlet compression system were designed [17], which is discussed below.

The SDPTE $(\mathrm{Hy}-\mathrm{V})$ program consisted of freejet and direct-connect testing in three separate facilities. The freejet testing took place at ATK GASL in both the NASA owned HyPulse shockexpansion tube, as well as GASL's Test Bay IV (TBIV) blowdown facility. The direct-connect testing took place in the UVaSCF. Whether or not the available test times in an impulse facility are long enough for the full establishment of the flow in a dual-mode scramjet is the subject of a separate study [18]. Therefore, the results from HyPulse will not be considered in this comparison study, and the analysis will focus on the data obtained from the TBIV freejet and UVaSCF direct-connect tests. The ground test campaign in the HyPulse and TBIV facilities included both Flowpaths A and B. The combustor geometry in Flowpath B was modified from the original UVa Flowpath A to allow for testing of higher equivalence ratios, but to minimize cost and leverage the existing hardware, Flowpath B was not tested in the directconnect configuration. As such, only the results from Flowpath A are considered in this study. The geometry for the flowpath is presented in Fig. 1. As discussed in [7] it is a rectangular, hydrogen fueled, dual mode scramjet with ramp fuel injection. As can be seen in the flight or freejet configuration in Fig. 1(a), at the entrance to the flowpath a forebody compression surface is seen to transition to the inlet and cowl geometry and into a constant area isolator with cross sectional dimensions of $2.54 \mathrm{~cm} \times 3.81 \mathrm{~cm}(1.0$ in $x 1.5 \mathrm{in}$ ). In order to minimize the risk of cowl induced unstart, the flowpath inlet design incorporated a $5^{\circ}$ droop at the cowl leading edge, which was intended to produce two weaker oblique shocks as opposed to one stronger one, decreasing the likelihood of the boundary layer separation on the opposing (bodyside) wall. The inlet was also designed such that the two shocks would strike the body-side wall downstream of the inlet throat, further preventing unstart and also promoting a restart of the engine should one occur. In order to further reduce the possibility of unstart and also increase the operational range of the engine, a $15.24 \mathrm{~cm}$ (6 in) isolator extension was incorporated into SDPTE (Hy-V) flowpath 
design from that of the original UVa DMSJ. Thus, in total the isolator extends $41.8 \mathrm{~cm}$ (16.47 in) from the inlet throat, at which point flow enters the combustor. The entrance to the combustor is defined by the leading edge of a $10^{\circ}$ un-swept ramp fuel injector, which has a normal height of $0.64 \mathrm{~cm}(0.25 \mathrm{in})$, a width of $1.27 \mathrm{~cm}(0.50 \mathrm{in})$, and a length of $3.75 \mathrm{~mm}(1.48 \mathrm{in})$. The fuel is injected at a Mach number of 1.7 parallel to the ramp compression surface. Immediately downstream of the fuel injector the flowpath regains the inlet duct dimensions which it maintains for $63.2 \mathrm{~mm}(2.49)$ inches before a $2.9^{\circ}$ divergence on the injection wall. This divergence forms the nozzle section of the engine and continues to the exit where the flow exhausts through a $40.8 \times 38.1 \mathrm{~mm}$ (1.605 in $\times 1.5$ in) cross sectional area.

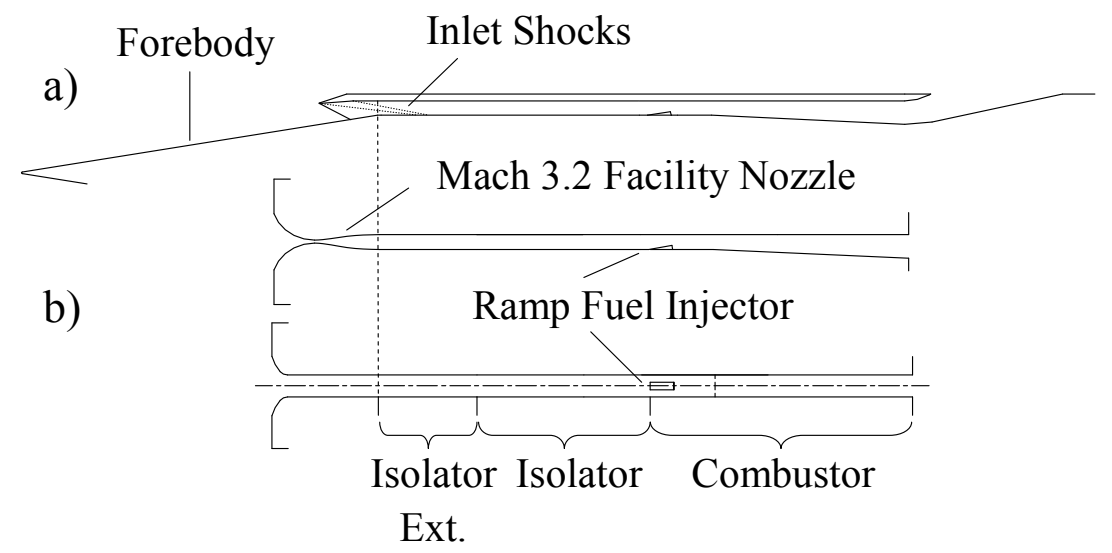

Figure 1. a) Flight and freejet dual-mode scramjet flowpath configuration, and b) direct-connect configuration. Dashed vertical line indicates plane extending from body-side shoulder (aka. inlet throat) and location of matched conditions.

Figure 1(b) also displays the direct-connect test article geometry. It can be seen that the directconnect facility nozzle exit plane corresponds to that of the inlet throat in the freejet and flight configurations. This is the location where conditions were matched between the two facilities. A new nozzle was fabricated for the UVaSCF to generate these conditions, for which more details are given below.

The UVaSCF is an electrically heated, continuous flow facility capable of simulating flight enthalpy conditions corresponding to Mach numbers near 5. A schematic of the facility is presented in Figure 3, and a detailed description of the facility is given by [16]. Of importance to note is that the facility is cleanly heated via electrical resistance coils staged upstream of the plenum, and is capable of a 
flow duration on the order of hours, which is primarily limited by fuel supply. The flow exhausts to atmospheric pressure at the exit of the flowpath and is directed out of the facility through an exhaust duct. As can be seen in Fig. 2, water vapor (in the form of steam), carbon dioxide and make-up oxygen can be added to the air flow to simulate a combustion vitiated facility. However, for the present study only the clean-air test results are considered.

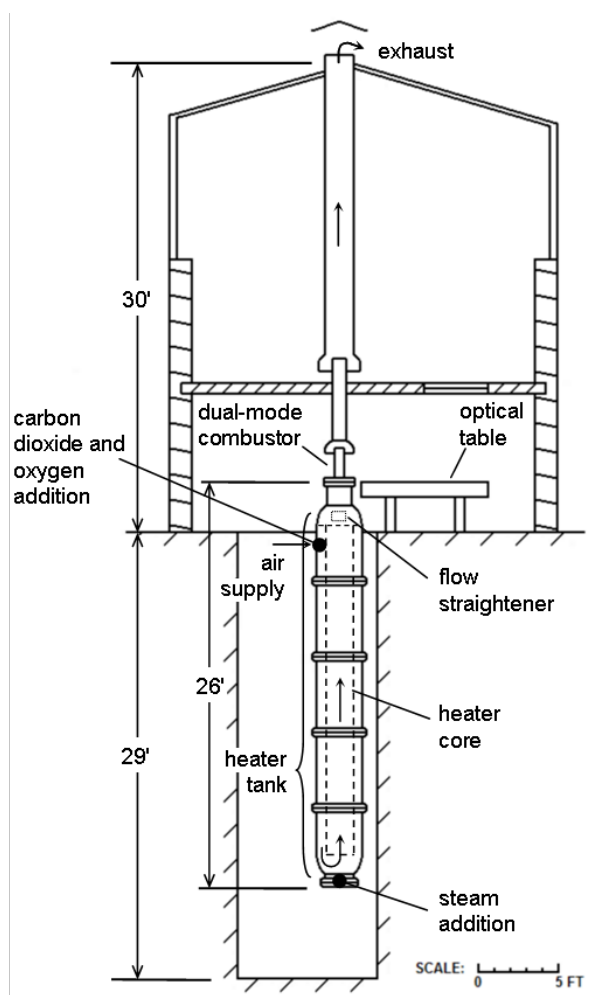

Figure 2. Schematic of UVa Supersonic Combustion Facility that was used for direct-connect tests.

Hydrogen fuel stored in a bottle farm outside the building is carried inside to the test article via $1 / 4$ " stainless steel tubing, which is approximately 60 feet long. The fuel pressure is controlled by a regulator attached approximately 15 feet upstream of the injector, and operated remotely from the control room. A Teledyne Hastings mass flow meter is used to determine the fuel flow rate, the readout of which is used to adjust the pressure regulator setting and subsequently the fuel equivalence ratio. 
Figure 3 provides a photo of the UVaSCF direct-connect test article. The facility nozzle was made entirely of Oxygen-Free High Conductivity (OHFC) Copper. The isolator extension was 303 stainless steel, however the original isolator and combustor were a combination of Nickel 200 and 304 stainless steel. All walls in the isolator and isolator extension were zirconia coated, along with the fuel injector ramp and fuel injector-side wall in the combustor. The test article and facility nozzle were cooled through a series of passages drilled into or brazed onto each component of the hardware. The coolant was a mixture of water and ethylene glycol.

During preliminary testing of the scramjet flowpath in the UVaSCF, it was established that the simplest method of ignition was to lower the flow total pressure and translate an exit shock train upstream into the combustor. With the fuel flow rate established, this prompted the flowpath to auto-ignite. Once stable combustion was achieved, the flow total pressure was then set to the nominal test value according to the test matrix.

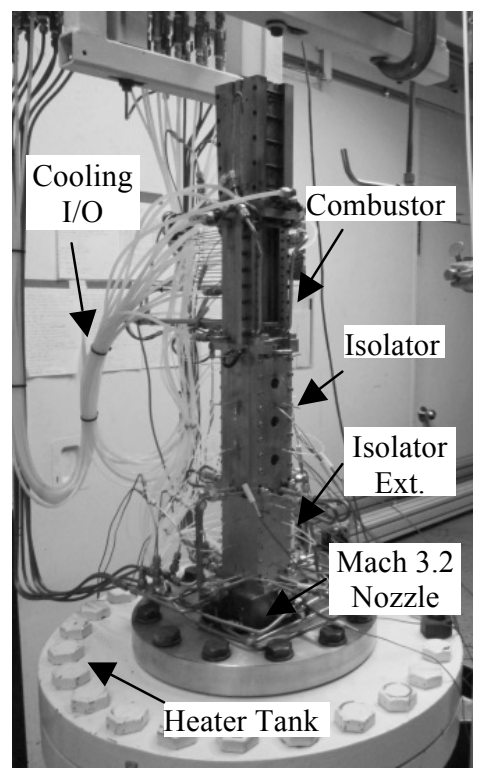

Figure 3. UVaSCF direct-connect test article.

Test article instrumentation consisted of a series of pressure taps spaced axially along the bodyside wall of the flowpath, the majority of which were located on the centerline. The instrumentation locations between the freejet and direct-connect test articles were designed to coincide as much as possible, and were for the most part in identical locations. In the UVaSCF, data acquisition of flowpath 
pressures was performed using a NetScanner pressure scanner. The sampling rate for pressure tap measurements was $10 \mathrm{~Hz}$, and the associated uncertainty for static pressure measurements was $\pm 0.05 \%$ of full scale, or $\pm 0.10 \mathrm{kPa}$. Facility mass flow for the direct-connect configuration was calculated using the facility nozzle via the standard choked flow equation with the measured plenum total temperature and pressure, and a CFD calibrated discharge coefficient. The associated air mass flow uncertainty was $\pm 1.1 \%$. Combined with a fuel mass flow uncertainty of $\pm 1.0 \%$, the calculated equivalence ratio uncertainty was $\pm 1.7 \%$.

TBIV is a blowdown freejet test facility capable of simulating flight enthalpy conditions corresponding to Mach numbers from 2 to 8 . For conditions up to Mach 5 the air is cleanly heated by a pebble bed, and for higher Mach numbers it can be heated via combustion. While the facility is of the blowdown type, at Mach numbers in the dual-mode regime the test time is approximately 30 seconds. This is more than adequate for the achievement of steady state in a DMSJ $[19,20]$. Figure 4 illustrates the integration of the freejet test article with TBIV. From the nozzle exit a jet stretcher (not shown) extends over the forebody and inlet to maintain the quality of the flow and prevent unwanted disturbances from propagating into the flowpath. The remainder of the flow not entering the engine is directed around the test article via a catchcone (also not shown) and towards the exit. It can be seen in Fig. 4, and more clearly in Fig. 5, that flowpaths A and B were operated side by side and shared the same forebody. However as described elsewhere [7], the flight design located the flowpaths on separate sides of the payload with separate forebodies. Returning to TBIV, at the exit of the flowpaths the flow exhausts through the diffuser and into a vacuum sphere.

Here, a clarification should be made about the definition of a freejet test and the distinction between this and what is referred to as a semi-freejet test. If aero appliances, such as the jet stretcher and catchcone described above, are used to contain the flow and direct it around the test article, or if the forebody is not geometrically simulated exactly as it would be on the flight vehicle, often the test is characterized more precisely as a semi-freejet. As such, the tests conducted in TBIV could be considered semi-freejet. However, due the focus on the effects of inlet distortion, which are representative of true 
freejet and are effectively simulated in the present semi-freejet configuration, the tests described in this paper are simply referred to as freejet.

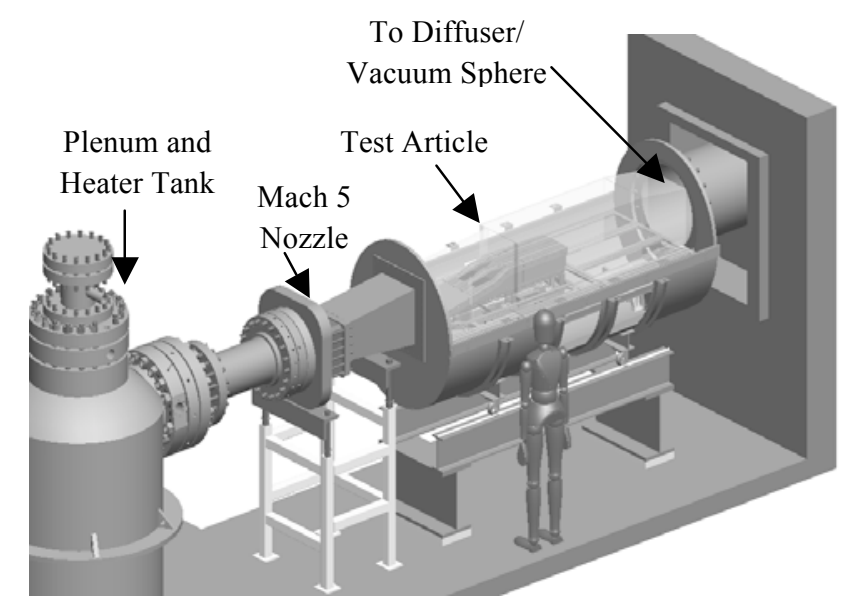

Figure 4. Test Bay IV and installed freejet test article.

Figure 5 shows a rendering of the TBIV test article. The forebody and flowpath apparatus were constructed entirely of OHFC Copper, and all four walls in both flowpaths were coated with zirconia. The test article was water cooled via passages drilled into the copper along the leading edges of the forebody and flowpath inlets. The test article was mounted on a pedestal assembly which positioned it at the exit of the facility nozzle and secured it to the floor. The pedestal, which was also water cooled, served to protect the instrumentation, fuel, and coolant lines from the freestream flow. The freejet test article flowpaths were placed far enough apart such that when both were fully started there would be no cross talk between the two inlets. Again, instrumentation consisted of pressure taps spaced axially along the body (injector)side wall of the flowpath, the locations of which were matched to those of the direct-connect test article and primarily along the centerline. A notable exception was one tap located in the ramp injector region which was placed off center in the freejet test article, but for which in the direct-connect article was located on the compression surface of the ramp. This is significant because these two taps are expected to read noticeably different pressures when a pre-combustion shock train is not present.

In TBIV a transition light-off technique was used to ignite the flowpath. This method employed a Silane fuel mixture (SFM) which was a 20/80 Silane/Hydrogen blend by mole fraction. In this set-up the 
SFM flow was initiated first and injected through the igniter port $\sim 2.5 \mathrm{~cm}$ downstream of the base of the ramp. Next, the primary Hydrogen fuel flow was started through ramp injector at the desired equivalence ratio. The lower activation energy of the Silane prompted autoignition, and once lit the SFM was ramped down leaving combustion and flame holding through the ramp fuel injector and on pure Hydrogen.

The TBIV pressure scanner is similar to that of the UVaSCF, along with the associated uncertainty of $0.05 \%$ full scale in the measured flowpath static pressures. The facility air and fuel mass flow rates are also calculated in a similar manner to that of the UVaSCF, leading to uncertainties of around $1.0 \%$ for each. Due to the use of the CFD predicted inlet mass capture in the determination of the equivalence ratio however, uncertainty for this value is not quantified.

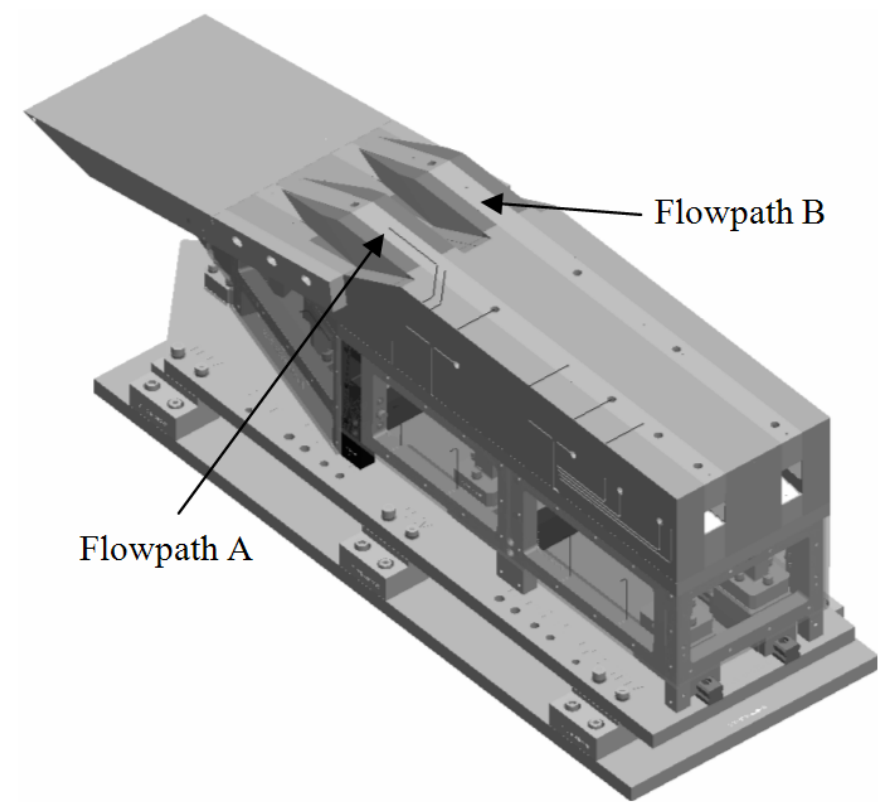

Figure 5. TBIV freejet test article.

The nominal test conditions were designed to replicate Mach 4.8 flight at a dynamic pressure of $77.8 \mathrm{kPa}$. A detailed explanation of the methodology used for determining the necessary UVaSCF directconnect conditions is given by DePiro [21]. In summary, the facility nozzle Mach number was designed to replicate the mass averaged isolator entrance Mach number determined from flight vehicle CFD performed at the test point [22](see vertical line in Figure 1). The results of which produced a 2D nozzle exit Mach number of 3.19. Figure 6 provides a comparison of the centerline Mach number distribution for 
the flight vehicle CFD at the isolator entrance with that of the UVaSCF nozzle exit. The curve presented for the UVaSCF direct-connect 2D nozzle design was determined from CFD performed in a separate study [23]. Static pressure and temperature at the same plane were determined from a 1-D analysis by simultaneously solving the aerothermodynamic equations with the same freestream conditions. While the CFD predicted the second cowl shock to pass through the isolator entrance plane, the static pressure and temperature values intended to be matched with the flight were those determined in the region downstream of that shock, which simplified the analysis.

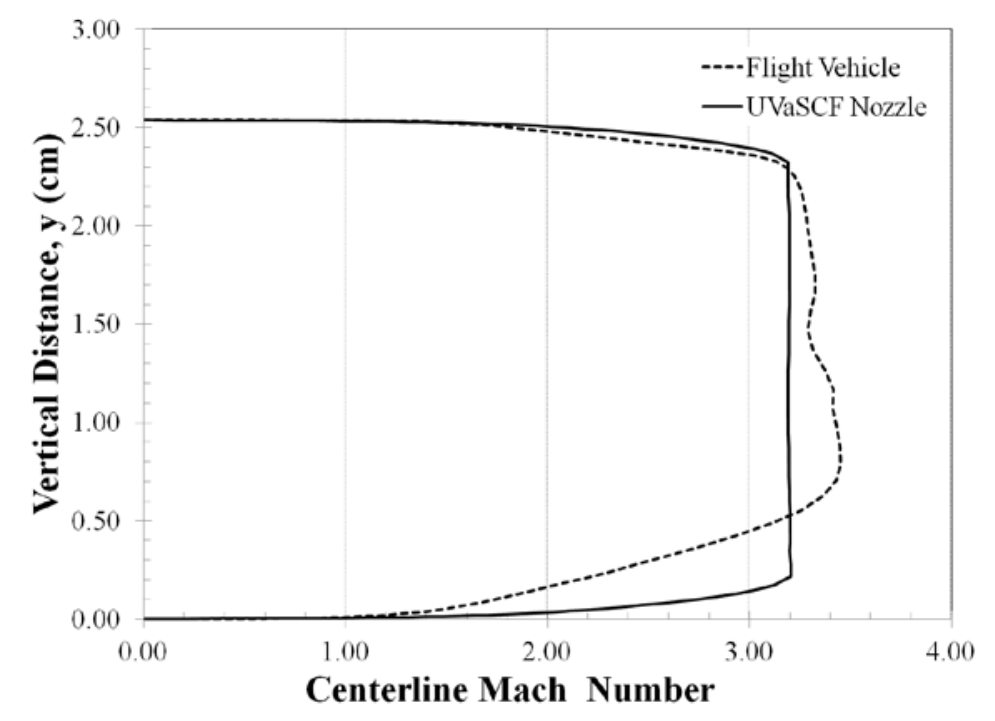

Figure 6. Centerline Mach number for UVaSCF direct-connect nozzle exit and flight vehicle isolator entrance. From CFD performed by [23] and [22] respectively. Dimension y extends vertically starting from body-side shoulder.

Ideally, the freejet facility nozzle exit would replicate the flight freestream conditions, and thus everything downstream would naturally be matched as well. However, the actual TBIV facility nozzle exit Mach number was in fact slightly higher than that of the nominal flight test point, so the flow properties were matched between the flight and freejet configurations at the cowl leading edge by manipulating the test article angle of attack. In this way both the TBIV freejet and UVaSCF direct Mach numbers were matched with the nominal flight conditions at the isolator entrance plane. Table 1 provides the nominal facility test conditions for both configurations along with the predicted flight conditions at 
the matched locations. All ground test values listed are derived from the facility plenum conditions using

1-D equilibrium flow analysis, unless otherwise noted.

Table 1. Nominal facility test conditions and corresponding predicted values at matched locations between direct-connect, freejet, and planned flight test point.

\begin{tabular}{cccc}
\hline \hline & UVa DC & TBIV Freejet & Flight \\
\hline \hline $\mathrm{M}_{0}$ at Nozzle Exit/Freestream & $3.20^{*}$ & 4.94 & 4.80 \\
$\mathrm{~T}_{0}$ at Nozzle Exit/Freestream, $(\mathrm{K})$ & 1161 & 1161 & 1161 \\
$\mathrm{P}_{0}$ at Nozzle Exit/Freestream, $(\mathrm{kPa})$ & 1060 & 2316 & 2213 \\
$\mathrm{~T}_{\mathrm{s}}$ Nozzle Exit/Freestream, $(\mathrm{K})$ & 378.2 & 207.2 & 217.2 \\
$\mathrm{p}_{\mathrm{s}}$ Nozzle Exit/Freestream, $(\mathrm{kPa})$ & 16.77 & 4.281 & 4.819 \\
$\mathrm{~h}_{0}$ at Nozzle Exit/Freestream, $(\mathrm{kJ} / \mathrm{kg})$ & 1238 & 1233 & 1233 \\
$\mathrm{Re}_{\mathrm{u}}$ at Nozzle Exit/Freestream $(1 / \mathrm{m})$ & $9.0 \times 10^{6}$ & $7.5 \times 10^{6}$ & $7.7 \times 10^{6}$ \\
$\mathrm{~T}_{\mathrm{s}}$ at Cowl Leading Edge, $(\mathrm{K})$ & - & 308.3 & 307.8 \\
$\mathrm{p}_{\mathrm{s}}$ at Cowl Leading Edge, $(\mathrm{kPa})$ & - & 14.19 & 14.19 \\
$\mathrm{Re}_{\mathrm{u}}$ at Cowl Leading Edge $(1 / \mathrm{m})$ & - & $1.1 \times 10^{7}$ & $1.1 \times 10^{7}$ \\
$\mathrm{p}_{\mathrm{s}}$ behind Cowl Shock II, $(\mathrm{kPa})$ & - & 34.80 & 34.80 \\
$\mathrm{~T}_{\mathrm{s}}$ behind Cowl Shock II, $(\mathrm{K})$ & - & 400.0 & 400.0 \\
Mach behind Cowl Shock II & - & 3.22 & 3.22 \\
Mach at Isolator Entrance & $3.20^{*}$ & $2.96^{* *}$ & $3.19^{* * *}$ \\
$\mathrm{Re}_{\mathrm{u}}$ behind Cowl Shock II $(1 / \mathrm{m})$ & - & $1.7 \times 10^{7}$ & $1.7 \times 10^{7}$ \\
Facility Mass Flow, $(\mathrm{kg} / \mathrm{s})$ & 0.196 & 11.6 & - \\
$\mathrm{Test}$ Article Mass Capture, $(\mathrm{kg} / \mathrm{s})$ & 0.196 & $0.272 * *$ & $0.254 * * *$ \\
Fuel Mass Flow, kg/s $(\varphi=0.66)$ & 0.00378 & 0.00523 & - \\
Fuel Mass Flow, kg/s $(\varphi=0.52)$ & 0.00297 & 0.00412 & - \\
\hline \hline
\end{tabular}

* Core flow Mach number determined from CFD at $\mathrm{T}_{0}=1209 \mathrm{~K}, \mathrm{P}_{0}=875.6 \mathrm{kPa}$, and $\gamma=1.39$ [21].

** Mass averaged quantities determined from freejet test article CFD at $\mathrm{T}_{0}=1218 \mathrm{~K}$ and $\mathrm{P}_{0}=2089 \mathrm{kPa}$, where mass capture was scaled by $\dot{\mathrm{m}}_{\mathrm{TBIVnom}} / \dot{\mathrm{m}}_{\mathrm{TBIV}}$ and adjusted with estimated correction due to jet stretcher expansion [22].

*** Mass averaged quantity determined from flight vehicle CFD performed at test point: $\mathrm{M}_{\infty}=4.8, \mathrm{p}_{x}=5.01 \mathrm{kPa}, \mathrm{T}_{x}=217.3 \mathrm{~K}^{1}$.

Upon examination of the conditions it is evident that total temperature and consequently total enthalpy were well matched between the two facilities. Due to facility constraints, however, the directconnect tests were conducted at a total pressure approximately half of that used in the freejet configuration. In order to compensate for this when comparing results, the direct-connect pressure distributions are scaled by the freejet mass capture, which is discussed in more detail below. Although scaling is required to compare pressure, it can be seen in Table 1 that Mach number and fuel equivalence ratios are also well matched, thus the foundation is adequately laid for a comparison between the directconnect and freejet test configurations.

\footnotetext{
${ }^{1}$ CFD support for SDPTE courtesy of Dr. William Engblom, Embry-Riddle University
} 


\section{Comparison Metrics}

To facilitate a quantitative comparison between freejet and direct-connect, a set of performance and operability metrics for the scramjet flowpath are now established. The performance metrics are those salient parameters which quantify the engine operation for a given fuel condition. The performance metrics of interest for this study are: isolator shock train length, shock train pressure ratio, and integrated pressure force in the divergent section. Isolator shock train length is defined in terms of fuel injector ramp heights, $\mathrm{L} / \mathrm{H}$, where $\mathrm{H}$ is the normal height of the ramp, and $\mathrm{L}$ is the length measured starting from the axial location of the most upstream extent of the pre-combustion shock train to the exit of the isolator, defined as the leading edge of the fuel injector ramp. The shock train pressure ratio, $\mathrm{p}_{\mathrm{d}} / \mathrm{p}_{\mathrm{u}}$, is defined as the ratio of the peak combustor pressure to the pressure at the leading edge of the shock train.

Due to inlet distortion, the determination of the upstream value of the shock train pressure ratio provides a complication in the case of the free jet testing. The oscillating nature of the shocks and expansions emanating from the isolator inlet produce a non-uniform flow over the height of the duct, and so the measured pressure on the body-side wall at the axial location of the leading edge of the shock train will not necessarily be the same across the entire duct. To compensate for this and provide a more representative pressure, a linear regression curve fit is determined for the pressures in the isolator. A curve fit is calculated for this region from the fuel off distributions for both configurations, which provides for a consistent definition of the upstream pressure for the shock train pressure ratio. Such a fit also furnishes a pseudo metric to help quantify how well the conditions are matched in the isolator between the two configurations.

The integrated pressure force is defined as:

$$
F=\int_{x_{1}}^{x_{2}} p(x) d A=y \tan (\varnothing) \int_{x_{1}}^{x_{2}} p(x) d x
$$

where $\mathrm{p}(\mathrm{x})$ is the pressure distribution measured from the axial location of the first pressure tap after the start of the area divergence, $\mathrm{x}_{1}$, to the axial location of the last pressure tap before the start of the exit shock train. For the freejet configuration where there is no exit shock train, $\mathrm{x}_{2}$ is set to be the same as that 
determined for the direct-connect configuration. For a flowpath where the area divergence is linear, the pressure force equation simplifies to that shown, where $\emptyset$ is the angle of the area divergence from the $\mathrm{x}$ axis, and y is the width of the duct. While Billig [22] proposed the use of the relationship for a polytropic process to fit the expansion pressure profile, a $3^{\text {rd }}$ order polynomial fit is used here to avoid any assumption of the nature of the process, which could mask any potential differences between the configurations. It is noted that the integrated pressure force is similar to an integrated thrust calculation, however the momentum and viscous drag terms have been excluded due to the complexities of the flow and the associated uncertainties which would arise from their inclusion in the calculation. The force defined here then, provides a metric for the comparison of the pressure distributions and the nature of the expansion in the divergent section of the flowpath. This type of analysis is akin to that used by Rockwell et al. [16], and is considered representative of the performance of the engine.

Operability metrics are those characteristics that define the limits of operation of the engine, i.e., ignition limits, blowout limits, unstart limits, and for dual-mode scramjets, mode transition. The latter is of particular interest here. While the repeatability and ease of ignition of the flowpath are also considered, the ignition, blowout and unstart limits are beyond the scope of this particular study. The operational mode of the engine is defined by the Mach number of the flow entering the combustor. In ram mode the bulk mass averaged flow is subsonic and characterized by an isolator shock train terminating in a normal shock. In the ram/scram or dual mode, an oblique shock train is typically present in the isolator, resulting in supersonic core flow entering the combustor surrounded by a subsonic, separated boundary layer. In the pure scram mode there is no pre combustion shock train and the flow is purely supersonic with an attached boundary layer. The process of mode transition involves the operation from the ram to scram mode, or vice versa, through the dual mode, and is typically characterized by the combustor entrance Mach number, $\mathrm{M}_{\mathrm{c}}$. The combustor entrance Mach number, and hence operational mode of the engine, can be determined in a 1-D sense using the analysis outlined by Rockwell et al. [16].This method was developed for application to direct-connect results and includes the use of Fanno flow to account for boundary layer growth along the walls upstream of the shock train. Since Fanno flow is only applicable 
for shock free uniform flow, the method is used here for the freejet test results by assuming that the expansion and compressions cancel at the isolator inlet and the relevant conditions are taken as those behind the second cowl shock, which were determined by the 1-D equilibrium analysis. Therefore, using this analysis method, the 1-D combustor Mach number and operational mode of the scramjet, in freejet and direct-connect, can be determined using measured flowpath pressures.

As mentioned above, the nominal total pressure for the direct-connect testing in the UVaSCF was approximately half of that for the TBIV freejet. While the isolator shock train length, shock train pressure ratio, and combustor entrance Mach number are all independent of the magnitude of the pressure, the integrated force calculation must be scaled in some way to compensate for this. In order to provide an accurate comparison of the force, the UVaSCF direct-connect pressures can be scaled accordingly:

$$
p=p_{s} \frac{\dot{m}_{\text {TBIVmc }}}{\dot{m}_{\text {test }}}
$$

where $p_{s}$ is the measured static pressure $\dot{m}_{T B I V m c}$ is the CFD predicted TBIV freejet flowpath mass capture, and $\dot{m}_{\text {test }}$ is the as tested UVa direct-connect facility mass flow rate (which varies from test to test). The CFD predicted freejet mass capture is used because the actual mass capture currently cannot be measured during a test. While scaling by an inlet reference pressure is common between tests in the same facility, due to the presence of inlet distortions this is not feasible when scaling in this study because a given tap at the inlet of the freejet flowpath is not necessarily representative of the pressure across the duct. Scaling by mass capture however, aligns the direct-connect total conditions with those at the isolator inlet in the freejet test, where the forebody and cowl will have lowered the total pressure and temperature from those values at the facility nozzle exit. This allows for the direct comparison of the integrated pressure force metric, as well as the qualitative comparison of the pressure distributions. In order to ensure the comparisons are fully consistent, the freejet pressures are scaled similarly by:

$$
p=p_{s} \frac{\dot{m}_{\text {TBIVnom }}}{\dot{m}_{\text {test }}}
$$


where $\dot{m}_{\text {TBIVnom }}$ is the nominal facility mass flow rate and $\dot{m}_{\text {test }}$ here is the as tested freejet facility mass flow rate (which also varies from test to test). Again, because mass capture cannot be measured during a test, the facility mass flow must be used to scale the freejet pressures, with which the actual mass capture is expected to scale accordingly. Scaling of all of the pressures also adjusts for run to run or in-run total temperature and pressure variations within each facility and ensures that all distributions are effectively being compared at the nominal test conditions.

\section{IV) Results}

The results of the testing and the subsequent comparison of the direct-connect and freejet configurations are presented below. First, the UVaSCF direct-connect pressure distributions over the range of equivalence ratios tested are provided to introduce the operation of the scramjet. Next, a set of equivalence ratios at varying total pressure conditions obtained in the UVaSCF are presented to examine the effects of back pressure on performance. Following this, the results obtained from the TBIV freejet tests are presented. After introduction of the results of each configuration and their relevant characteristics, a set of plots are provided comparing the pressure distributions for the fuel equivalence ratios matched between the two configurations. Finally, the performance and operability metrics are presented, accompanied by an analysis and discussion of the comparison study.

The results from the UVaSCF direct-connect testing are presented in Fig. 7, where stable combustion was achieved over a range of equivalence ratios representative of the scram, scram/ram, and ram operational modes. Ignition was typically carried out at equivalence ratios close to 0.35 , where stable combustion was achieved at 0.39 . The ignition process was found to be robust and repeatable. As described above, all direct-connect pressures are scaled according to Eq. (2). Good agreement is seen between the fuel off distribution and the portion of each fuel on distribution upstream of the shock train, indicating good flowpath and facility repeatability, and the effectiveness of the scaling to eliminate 
resident fluctuations in facility total pressures and temperatures. At $\pm 0.10 \mathrm{kPa}$, the error bars for all direct-connect pressures are smaller than the provided symbols in the figure.

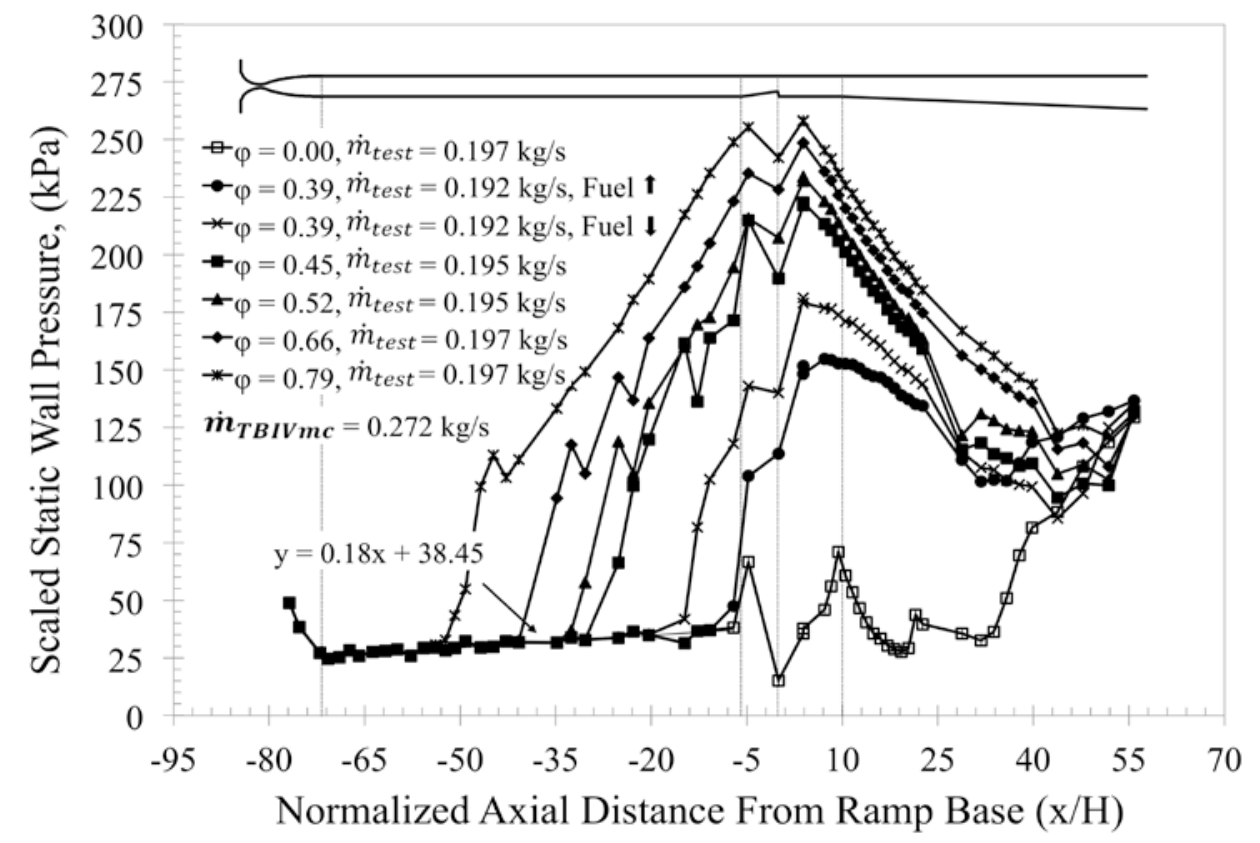

Figure 7. Scaled axial pressure distribution from direct-connect testing in the UVaSCF, together with flowpath geometry.

As expected, the flow in the isolator for the fuel off distribution is very uniform, where the growth of the boundary layers causes a steady pressure rise in the isolator as it progresses towards the combustor. The change in pressure upstream of $\mathrm{x} / \mathrm{h}=-67$ is the expansion in the facility nozzle (which is neglected when comparing with the free jet data below). Also shown in the figure, the linear regression is seen to provide a good fit for the fuel off pressures along the length of the isolator. The lowest equivalence ratio for which steady combustion was achieved was 0.39 . The "fuel increasing" distribution at this equivalence ratio was the only condition for which operation entirely in the scram mode was observed. This is evidenced by the lack of a shock train upstream of the leading edge of the ramp fuel injector, indicating purely supersonic flow in a 1-D sense. The "fuel decreasing" distribution at the same equivalence ratio however, has a clear isolator shock train and a higher combustor pressure. This hysteresis is typical in a DMSJ, and is well documented [16,23]. For the tested equivalence ratios above 
0.39 the hysteresis was not observed, and the shock train length increases as expected with increasing combustor pressure. While not shown, excellent repeatability was observed for the direct-connect tests.

As discussed above, the scramjet flowpath in the UVaSCF exhausts to atmospheric pressure. This results in a backpressure on the flowpath that is reflected in the pressure distributions in Fig. 7 for axial locations greater than $\mathrm{x} / \mathrm{H}=36$. Since the TBIV facility exhausts to a vacuum system, a study was first conducted in the UVaSCF wherein the effects of back pressure could be examined. While the UVaSCF does not have the capability to control back pressure directly, the facility total pressure was adjusted instead such that the change in pressure ratio effectively simulated a change in back pressure. Figure 8 displays the scaled pressure distributions for three different equivalence ratios and three different total pressures. The equivalence ratios span the dual mode regime, where fuel off, scram, and $\mathrm{ram} / \mathrm{scram}$ mode are all represented.

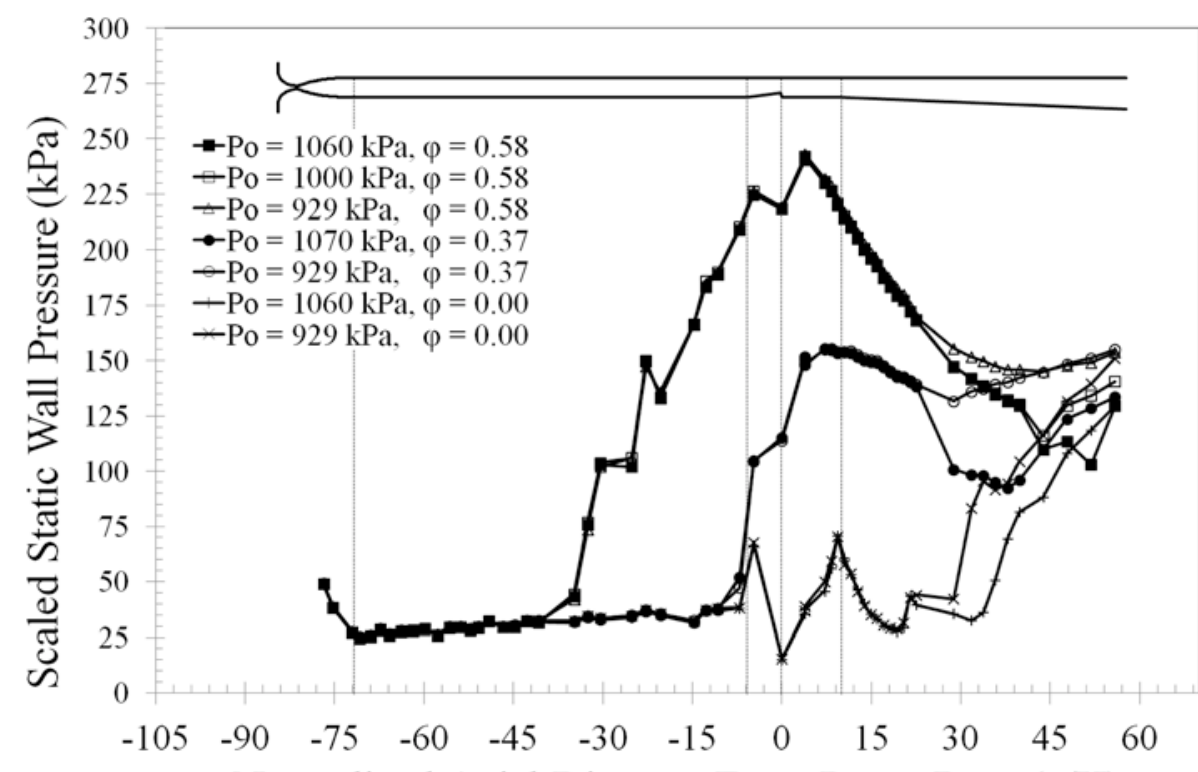

Normalized Axial Distance From Ramp Base (x/H)

Figure 8. Influence of varying the ratio of total pressure to exit pressure on scaled axial pressure distribution in direct-connect tests, exit pressure $=1 \mathrm{~atm}$.

It can be seen in Fig. 8 that, for all equivalence ratios and all ratios of total pressure to back

pressure, there is no influence of the back pressure upstream of $x / H=23$. If the flow is supersonic, this influence manifests itself as a shock train that matches the combustor pressure with the atmospheric exit 
pressure. As would be expected, this shock train grows in length as the ratio of the total pressure to back pressure is decreased. This shock train exists for all conditions in Fig. 8 except for the lowest total pressure condition at the highest equivalence ratio, where the flow appears to remain subsonic throughout the combustor. It is therefore concluded that if this exit shock train is present, then the axial development of the combustion process is unaffected up until the leading edge of the exit shock train. This finding is conducive to the comparison of data between the two facilities, and as TBIV exhausts to a vacuum in which there is no formation of an exit shock train, the downstream most location for which a comparison can be conducted is the axial location in the direct-connect configuration where the exit shock train is seen to begin. As can be seen in Figs. 7 and 8, for the nominal test point of $1060 \mathrm{kPa}$ (provided in Table 1), this corresponds to an $\mathrm{x} / \mathrm{H}=40$. This is important for the selection of the $\mathrm{x}_{2}$ coordinate, which is used in the determination of the integral pressure force.

Attention is now turned to the data from the freejet testing in the TBIV facility which is presented in Fig. 9. Due to ignition difficulties and the duration of the test campaign, the data set was limited to equivalence ratios of $0.00,0.52$, and 0.66 . For reasons unidentified by the investigators, the adopted ignition process was not repeatable over a range of equivalence ratios. However, once combustion was established the operation of the flowpath was repeatable. The results from the two runs in which the equivalence ratios were similar, (to within experimental uncertainty), are presented to demonstrate the repeatability of the freejet testing once ignition occurred. The freejet distributions are scaled by mass flow rate according to Eq. (3). The differences between peak pressures at each equivalence ratio are less than $2.0 \%$, and overall, good repeatability is observed. Given the good repeatability, the run 1 pressures are considered representative and are used solely in the subsequent comparisons of the freejet and directconnect configurations. 


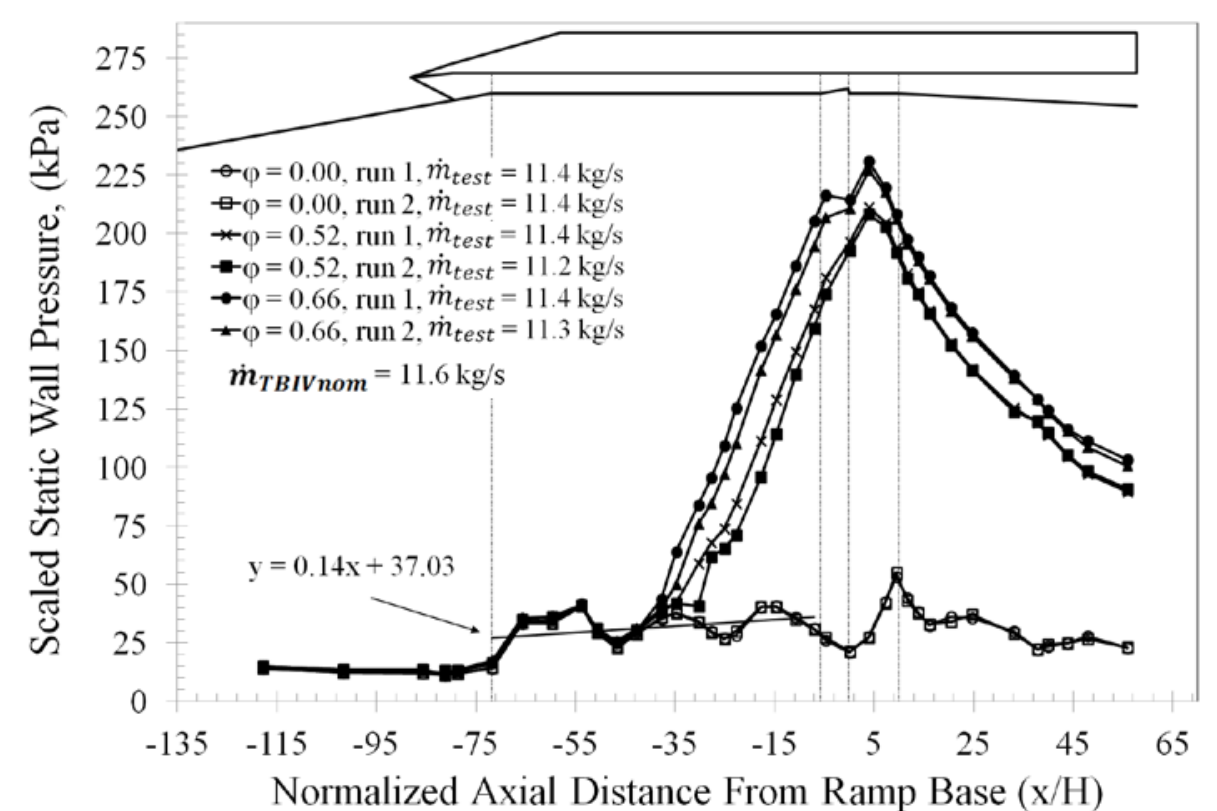

Figure 9. Scaled axial pressure distributions from the TBIV freejet testing with linear regression for isolator pressures for the fuel off case.

Returning to the results in Fig. 9, it can be seen that the operation of the flowpath is very similar in characteristic to that observed for direct-connect. However, in the freejet case the inflow to the isolator is affected by the presence of the inlet and the combustor outflow is not influenced by the one atmosphere back pressure. As is expected, the pressure along the forebody is relatively constant upstream of $\mathrm{x} / \mathrm{H}=$ 75. At $\mathrm{x} / \mathrm{H}=-67$ it can be seen that there is a pressure increase due to the presence of the two cowl induced shocks. For the fuel off case the pressure then fluctuates axially along the isolator due to the reflection of inlet induced shocks and expansion fans. These fluctuations are the core evidence of the presence of inlet distortion. The fluctuations in the isolator for the fuel off distributions are seen to be generally uniform and are bisected by the linear regression fit. Interestingly, the slope and intercept of the regression agree very well with those produced by the fit of the direct-connect data, providing confidence that the conditions were well matched between the two facilities and the scaling of the direct-connect distributions by the predicted freejet mass capture is effective. For both the 0.52 and 0.66 equivalence ratios, it can be seen in Fig. 8 that combustion is vigorous and there is a well defined pre-combustion shock train in the isolator. As discussed further below, this is indicative of operation in the dual mode. 
The three equivalence ratios for which results were obtained in the freejet configuration are the equivalence ratios around which this comparison study will focus. Figure 10 presents the comparison of the freejet and direct-connect pressure distributions for the equivalence ratios of 0.00 and 0.52 . Figure 11 presents the comparison at the second fuel on equivalence ratio of 0.66 , again referenced against the fuel off data.

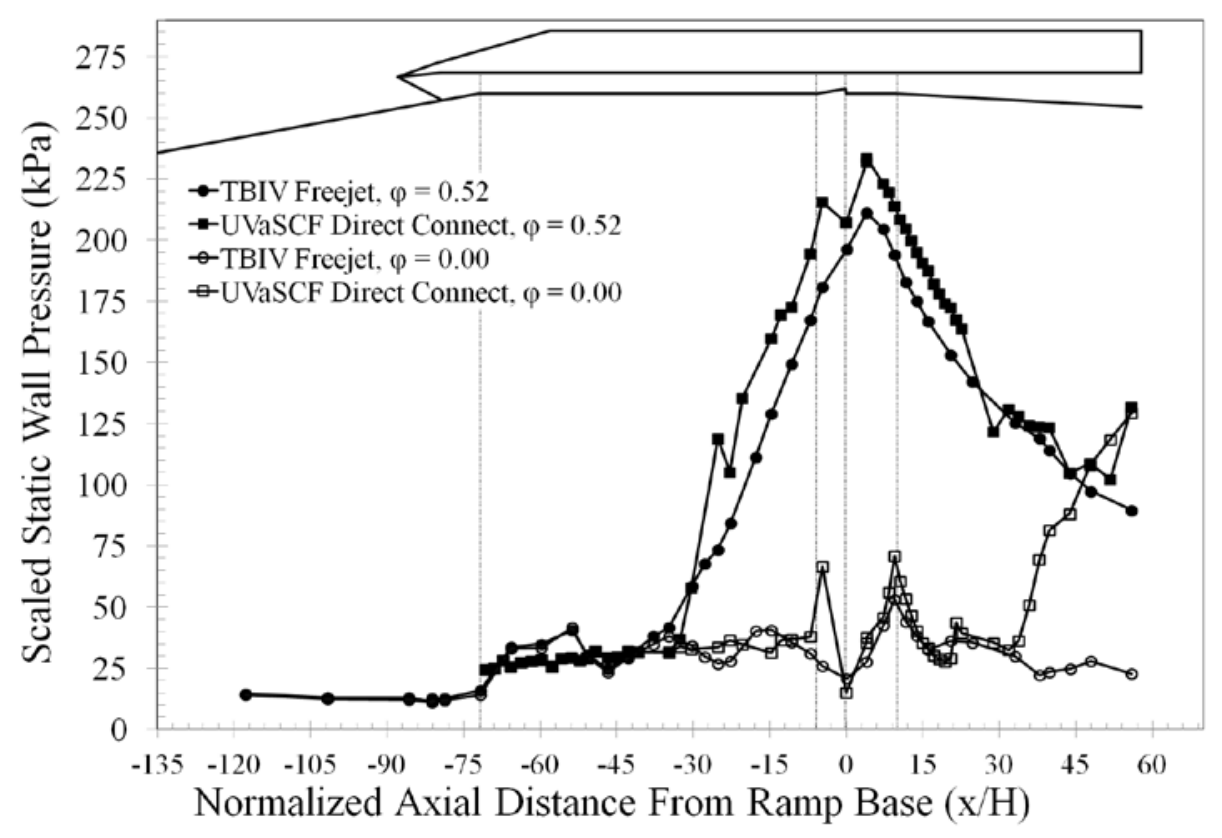

Figure 10. Comparison of direct-connect and freejet pressure distributions for $\boldsymbol{\phi}=\mathbf{0 . 5 2}$. 


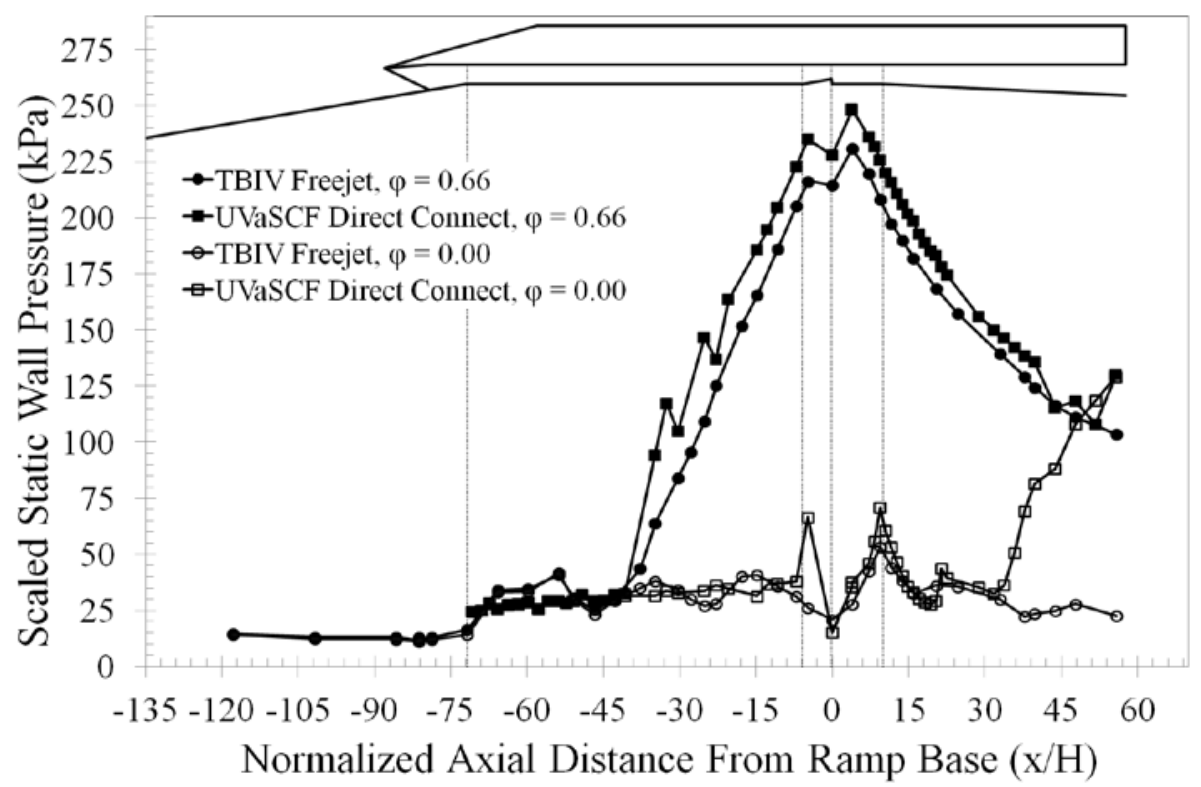

Figure 11. Comparison of direct-connect and freejet pressure distributions for $\phi=0.66$

Examination of the fuel off distributions shows good agreement between the freejet and directconnect configurations. As predicted by the similarity of the isolator regression fits discussed above, when compared on the same plot, the direct-connect pressures in the isolator bisect those of the freejet distribution. In the fuel injector region of the direct-connect profile, between $\mathrm{x} / \mathrm{H}=-6$ and 0 , a steep compression followed by a rapid expansion is observed, whereas in the freejet profile only the continuation of the oscillating compressions and expansions is seen. This discrepancy is due to a difference in the transverse location of the tap at $\mathrm{x} / \mathrm{H}=-5.9$, as discussed in the test article section, which placed it beside the ramp and outside of the compression experienced on that surface. Downstream of the location of fuel injection, the reflected compression waves generated by the ramp cause a pressure rise at $\mathrm{x} / \mathrm{H}=9$ in both the free jet and direct-connect distributions. In this region the two profiles show the same general trend, however it is clear that the freejet peak pressure only reaches about $80 \%$ of that of that seen in the direct-connect profile. This difference is likely due to a combination of the presence of the inlet expansions as well as the larger body-side boundary layer thickness in the freejet configuration. Through the divergent section both profiles exhibit the expected expansion. As the flow approaches the exit a welldefined shock train is seen in the direct-connect profile as it exhausts to the atmospheric back pressure. In 
the freejet profile the distribution levels off as it exhausts to the pressure existing in the wake of the test article, where the freejet test chamber exhausts to a vacuum sphere. Not including the exit shock train in the direct-connect case, the distributions show very good agreement in the overall trends and magnitudes of the pressures, particularly at the inlet and in the isolator region. The observed similarities here provide confidence that the isolator inflow conditions are well matched, which establishes the baseline for the comparison of the fuel on distributions.

Qualitatively, the initial inspection of both combusting cases in Figs. 10 and 11 shows very similar trends between the two test configurations. The shape, location, and amplitude of the combustor pressurization are all in relatively good agreement. In particular, the location of peak pressure is seen to occur at the same axial location in both configurations, which is at $\mathrm{x} / \mathrm{H}=4$. Interestingly, the magnitudes of the freejet peak pressures are approximately $90 \%$ of those in the direct-connect. It is evident that for the part of the flow affected by combustion, from the shock train leading edge in the isolator, through the combustor, and to the leading edge of the downstream shock train in the direct-connect case $(\sim-40<\mathrm{x} / \mathrm{H}$ $<40$ ), the two configurations exhibit very similar profiles. In addition, the freejet pressures are generally a consistent sub-unity fraction of those in the direct-connect. The general shape of the shock train shows some variation between the two configurations, and while the flow in this region is generally quite complex, it is possible that the brief drops in pressure observed only in the direct-connect distributions are the result of a slight hardware misalignment between the isolator extension and the isolator. Further, it can be seen that the isolator shock train length appears to be similar for the freejet and direct-connect case for both equivalence ratios. This is explored in more detail below.

In order to quantify these observed similarities and differences, the previously established performance metrics are provided in Table 2. For both fuel on cases, excellent agreement is observed for the shock train length between the direct-connect and freejet configurations. The uncertainty associated with these values is dictated by the spacing between pressure taps. In this section of the isolator the taps were anywhere from 2 to 5 ramp heights apart, which leads to the uncertainties given in the table. 
Nonetheless, it is seen that the correlation between shock train length and equivalence ratio behaves in a similar manner for both configurations and that there is good agreement in both location and magnitude.

Table 2. Performance metrics for direct-connect and freejet.

\begin{tabular}{ccccc}
\hline \hline $\begin{array}{c}\text { Equivalence } \\
\text { Ratio, } \boldsymbol{\varphi}\end{array}$ & Test Configuration & $\begin{array}{c}\text { Isolator Shock Train } \\
\text { Length, } \mathbf{( L / H )}\end{array}$ & $\begin{array}{c}\text { Shock Train Pressure } \\
\text { Ratio, }\left(\mathbf{p}_{\mathbf{d}} / \mathbf{p}_{\mathbf{u}}\right)\end{array}$ & $\begin{array}{c}\text { Integrated Pressure } \\
\text { Force, } \mathbf{F}(\mathbf{N})\end{array}$ \\
\hline \multirow{2}{*}{0.52} & Freejet & $29 \pm 5$ & $6.6 \pm 0.2$ & $49.4 \pm 2.5 \%$ \\
& Direct-connect & $29 \pm 2$ & $7.2 \pm 0.1$ & $55.6 \pm 2.5 \%$ \\
\hline \multirow{2}{*}{0.66} & Freejet & $37 \pm 5$ & $7.4 \pm 0.1$ & $54.3 \pm 2.5 \%$ \\
& Direct-connect & $37 \pm 2$ & $8.1 \pm 0.1$ & $61.3 \pm 2.5 \%$ \\
\hline \hline
\end{tabular}

Returning to Table 2, as expected from the trends observed in Figs. 10 and 11, the freejet shock train pressure ratios are approximately $90 \%$ of those experienced in the direct-connect configuration (for both equivalence ratios). The uncertainties given for each pressure ratio are determined using the uncertainties in the respective shock train lengths, in other words the deviation calculated using the axial location of the next upstream tap from that used for the shock train leading edge. It is interesting to note the excellent agreement in shock train length and yet the consistent difference in the pressure ratio. The relationship between the two has been well studied, and the empirical formula put forth by Waltrup and Billig is often cited [24].

$$
\frac{L}{D}=\frac{\sqrt{\frac{\theta}{D}}}{\sqrt[4]{R e_{\theta}}} \frac{\left\{50\left(\frac{p_{d}}{p_{u}}-1\right)+170\left(\frac{p_{d}}{p_{u}}-1\right)^{2}\right\}}{M_{u}^{2}-1}
$$

Here, $\theta$ is the boundary layer momentum thickness at the upstream location, $\mathrm{u}$, and is also designated as the characteristic length for the Reynolds number. $\mathrm{D}$ is the isolator duct height; which is related to the ramp normal height, $\mathrm{H}$, here by $\mathrm{H}=\mathrm{D} / 4$. It is clear simply from examination of the equation that in order to produce the same shock train length with a lower pressure ratio, as is seen to be the case in the freejet configuration, the boundary layer thickness must be larger. This is in fact known to be the case for the freejet flowpath because of the growing boundary layer along the test article forebody. Indeed, employing the measured values for shock train length and pressure ratio in the above relation, and using the unit Reynolds number for each configuration (where density in the direct-connect is $\sim 1 / 2$ that in the freejet), provides a freejet boundary layer momentum thickness approximately 4.4 times that of the direct- 
connect. This value is on the order of that predicted by the CFD in Figure 6, and explains why the shock train length is the same in Figs. 10 and 11 and yet the combustor pressures are lower for freejet relative to direct-connect. Of course, this explanation assumes that the inlet compressions and expansions, along with any differences in corner flow and sidewall boundary layer thickness between the two configurations, do not have a strong effect on the shock train length.

It is important here to consider the scope of the equivalence ratios for which a comparison of the configurations is available. It would be most beneficial to fill out the freejet data set with further fuel on cases to see whether or not the shock train lengths and pressure ratios in fact maintain the observed similarities and differences, respectively, between the direct-connect and freejet configurations. It is possible, as observed in [6], that for the higher equivalence ratio cases in the ram mode where the precombustion shock train is near the inlet the flow distortions will have a larger impact on shock train length. Conversely, for the scram mode where there is no shock train upstream of the combustor entrance, and smaller compression emanating from the ramp leading edge, it is conceivable that the inlet distortions will have a somewhat different impact on the conditions in the combustor and the subsequent pressure rise.

There still remains the question as to why the combustor pressures are different. It is possible that the inlet shock-expansion system and larger body-side boundary layer experienced in freejet testing affect the fuel-air mixing in the wake of the injector, altering the combustion efficiency, and ultimately contributing to the lower pressure rise. This hypothesis is supported by the fact that combustion under these conditions is largely mixing limited. The boundary layer in the vicinity of the fuel injector has been established above to be larger for freejet and this would reduce the effectiveness of vorticity generation by the ramp fuel injector. This could be coupled with larger boundary layer separation induced by the isolator shock train as well, which would further alter the inflow to the fuel injector and reduce injector mixing effectiveness.

It is worth considering here the potential role that the absolute magnitude of the pressure might play in the chemical kinetics of combustion. While the chain branching reaction rate in a Hydrogen- 
air combustion process increases linearly with pressure, the three body termination reaction rate increases with the square of the pressure. As explained by Pulsonetti et al. [25], this is thought to have a potentially limiting affect on the axial combustion progression as the combustor inlet pressure is increased. However, for a single flowpath at the same scale, their results showed that as the combustor inlet pressure was increased, the magnitude of the pressure rise also increased, by about $20 \%$ for a $250 \%$ increase in inlet pressure. While these tests were for a much higher flight Mach number simulation, and combustion was in the scram mode, a relevant inference can be made here. The observed trends of [25] are in opposition to those of the current study where the freejet flowpath, which had a static pressure upstream of combustion approximately twice that of the direct-connect, exhibited a lower combustor pressure rise. This would seem to indicate that the opposing effect of another phenomenon has an overall predominant influence on combustor pressure rise in this study, possibly that of the increased boundary layer momentum thickness as discussed above.

To complete the discussion of Table 2, attention is paid to the integrated pressure force. The $3^{\text {rd }}$ order polynomial used for the determination of the integrated force generally provided a very good fit for the pressure distributions in the expansion section. The one exception was for the $\varphi=0.52$ case in the direct-connect configuration in Fig. 10. The steep drop in pressure observed at $\mathrm{x} / \mathrm{H}$ of $\sim 30$ for this case was most likely due to thermal growth and resultant hardware misalignment between the separate components making up the test article in this region. This was also the conclusion of Gupte et al. [26], who employed the use of FEA and CFD to confirm the observed drop. Comparing the force between the two configurations, it is again seen that the freejet values are approximately $90 \%$ of those calculated for the direct-connect configuration. This is consistent with the trends observed for the shock train pressure ratio and those of the pressure magnitudes in Figs. 10 and 11.

With the effects of inlet distortion on performance established, operability is now examined. The combustor entrance Mach number is the parameter which defines the operational mode of the engine, and is presented in Fig. 12 as a function of equivalence ratio. The horizontal line corresponding to Mach 1 is emboldened to highlight where the flow transitions from supersonic to subsonic combustion. 


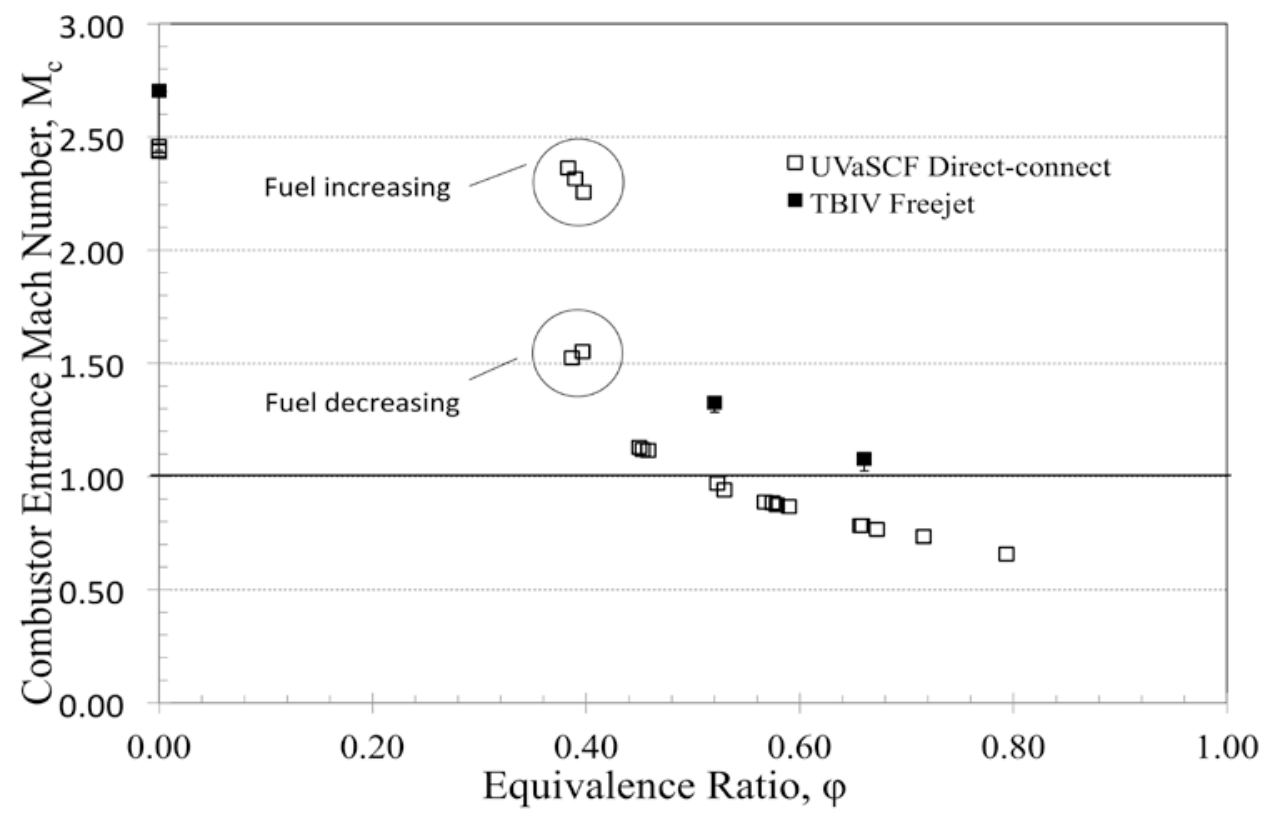

Figure 12. Operability Metric, combustor entrance Mach number vs. fuel equivalence ratio. Data affected by hysteresis labeled.

The trend clearly indicates that as fuel, and heat release, is increased and the shock train is pushed forward, the Mach number decreases. Whereas mode transition is seen to occur somewhere around an equivalence ratio of 0.5 for the direct-connect data, it is clear that the freejet transition occurs later, likely between 0.7 and 0.8 . This is due primarily to the lower shock train pressure ratios exhibited by the freejet results.

While not a quantitative metric, another factor to take into consideration in terms of operability is that of ignition. As mentioned above, a lack of ignition repeatability was the cause of the limited results obtained in the freejet testing. When considering this, it is important to first recall the differences in ignition methodology used between the two configurations. In the direct-connect testing, due to the longer duration run times, it was possible to lower the total pressure and bring the exit shock train farther upstream into the combustor, and this resulted in autoignition. In contrast, a 20\% SFM was injected in the freejet configuration through the igniter port to promote ignition, and once lit, the Silane was ramped down. While the different techniques do not enable a direct comparison of flowpath ignition characteristics, the results do point to key differences between the ability of the direct-connect and freejet 
configurations to ignite. Even without further data, however, the observations do serve to highlight the importance of taking into account ignition characteristics when conducting a direct-connect ground test campaign and extrapolating to freejet and flight, particularly if there are subtle differences in the test techniques.

\section{V) Conclusion}

Testing of identical dual-mode scramjet flowpath geometries in the freejet and direct-connect configurations were conducted in the ATK GASL Test Bay IV blowdown facility and the University of Virginia Supersonic Combustion continuous flow facility, respectively. The tests enabled a determination of the effects of inlet distortion and back pressure on the performance and operability of a dual-mode scramjet. Conditions were matched between the two facilities at the isolator entrance plane to simulate Mach 4.8 flight. A series of performance and operability metrics were established to quantify the similarities and differences of the results produced in the two different configurations. While the directconnect tests were conducted at a facility total pressure approximately half that of the freejet, the pressure distributions were scaled by the predicted freejet inlet mass capture to effectively compare the pressure distributions and relevant performance metrics.

Testing produced a set of three equivalence ratios for which data was available to compare the results from the direct-connect and freejet configurations, which were $\varphi=0.00,0.52$, and 0.66 . In all three cases, qualitatively, good agreement was observed in the overall trends and locations of the major flow features in the axial pressure distributions.

In summary, the effects of inlet distortion and back pressure on the performance and operation of the dual-mode scramjet of this study, caused by the differences inherent in testing between the directconnect and freejet configuration, are as follows:

Performance:

- Back pressure on the flowpath alters the axial location of the exit shock train leading edge, but does not affect the performance of the scramjet upstream of that location, 
- The isolator shock train length is unaffected by inlet distortion,

- Pressure rise due to combustion and subsequent shock train pressure ratio are reduced by $\sim 10 \%$ from the freejet to direct configuration, and

- The freejet integrated pressure force is reduced in magnitude corresponding to that of the shock train pressure ratio, but is otherwise unaffected by any propagation of the inlet distortion.

Operability:

- For an increasing equivalence ratio, mode transition (in a one dimensional sense) appears to be delayed from $\varphi \sim 0.5$ in the direct-connect configuration to $\varphi \sim 0.7$ in freejet, and

- A lack of ignition repeatability was observed in freejet as opposed to robust and reliable ignition in the direct-connect. However, further testing is required to identify the dependence on the different ignition techniques adopted for each configuration.

This work resulted in several findings that are important for the interpretation of direct-connect testing and its subsequent extrapolation to freejet and flight. First, for this particular dual-mode scramjet at the conditions tested, inlet distortion had only minor effect on performance. Therefore, with the appropriate correction, this study points to the possibility that performance results for this scramjet in direct-connect could be extrapolated to freejet or flight. However, much more data is needed to augment the current dataset of the present study. When operability is considered, the study suggests that directconnect results could not be directly extrapolated to flight, where the point of mode transition could be significantly affected. In addition, while still an open question, ignition characteristics for the flow path could also be different. These differences then suggest that freejet testing is still a critical component of a ground test campaign in going from direct-connect to flight. Finally, with the caveat that there are some performance and operability differences, the results of the present study do support the assertion that direct-connect test data from the UVaSCF captures many of the characteristics of freejet operation. It is 
therefore concluded that past and future scientific studies in this facility can and do adequately capture many of the key physics of dual-mode scramjet operation.

While the scope of this investigation was small, the results of the present study are particularly encouraging for large-scale scramjet ground testing in direct-connect facilities that may be the only option for some future technology development. However, in order to fully understand how best to extrapolate direct-connect results to flight where freejet data is unavailable, much more testing is required over a complete range of equivalence ratios and a wider range of flight conditions. Even with this caveat, this study does add important insight into the effects of inlet distortion and back pressure on the performance and operability of dual-mode scramjets and it provides a framework for necessary future studies.

\section{Acknowledgements}

The author would like to thank Test Resource Management Center (TRMC), Test and Evaluation/Science and Technology (T\&E/S\&T) Program for their support. This work is funded by the T\&E/S\&T Program through High Speed Systems Test (HSST). In addition, this work was made possible by the tests conducted at ATK GASL, and thanks go to Dan Cresci, Ching-Yi Tsai, and Akiva Sklar. The author also wishes to express appreciation to his adviser Dr. Chris Goyne, as well as Dr. Robert Rockwell and Mr. Roger Reynolds, for their invaluable help and guidance, along with the University of Virginia Department of Mechanical and Aerospace Engineering for their support in the pursuit of my degree. The programmatic and technical guidance from Mr. Jon Osborne, Dr. Roy Schulz, and Mr. Wade Burfitt of MIRATEK Corporation, Inc. is also very much appreciated. 


\section{Sources}

[1] Heiser, W. H., and Pratt, D. T., Hypersonic Airbreathing Propulsion, AIAA Education Series, AIAA, Washington, D.C., 1994, pp. 528-537.

[2] U.S. Energy Information Administration, "FAQ: How much electricity does a typical nuclear power plant generate?," EIA.gov, July 2012, [http://www.eia.gov/tools/faqs/faq.cfm?id=104\&t=3].

[3] Bakos, R. J., Castrogiovanni, A., and Calleja, J. F., "Expansion of the Scramjet Ground Test Envelope of the HYPULSE Facility," $7^{\text {th }}$ International Space Planes and Hypersonic Systems and Technologies Conference, Norfolk, VA, AIAA Paper 96-4506, 1996.

[4] Erdos, J. I., "On the Bridge from Hypersonic Aeropropulsion Ground Test Data to Flight Performance," 20th AIAA Advanced Measurement and Ground Testing Technology Conference, June, 1998. doi: 10.2514/6.1998-2494.

[5] Emami, S., Trexler, C.A., Auslender, A.H., and Weidner, J.P., "Experimental Investigation of InletCombustor Isolators for a Dual-Mode Scramjet at a Mach Number of 4," NASA Technical Paper 3502, May, 1995.

[6] Tan, H.J., Sun, S., and Huang, H.X., "Behavior of Shock Trains in a Hypersonic Inlet/Isolator Model with Complex Background Waves," Experiments in Fluids, December, 2012, Vol 53, Issue 6.

[7] Goyne, C. P., Cresci, D., and Fetterhoff, T., "Short Duration Propulsion Test and Evaluation (Hy-V) Program," 16th AIAA/DLR/DGLR International Space Planes and Hypersonic Systems and Technologies Conference, AIAA Paper 09-7296, October, 2009.

[8] McClinton, C. R., Voland, R. T., Holland, S. D., and Engelund, W. C., "Wind Tunnel Testing, Flight Scaling and Flight Validation with Hyper-X”, AIAA Paper 98-2866, 1998.

[9] Faulkner, R. F., and Weber, J. W., "Hydrocarbon Scramjet Propulsion System Development, Demonstration, and Application," AIAA Paper 99-4922, 1999.

[10] Hank, J.M., Murphy, J.S., and Mutzmann, R.C., "The X-51A Scramjet Engine Flight Demonstration Program," AIAA Paper 08-2540, 2008.

[11] Boyce, R. R., Paull, A., Stalker, R. J., Wendt, M., Chinzei, N., and Miyajima, H., "Comparison of Supersonic Combustion Between Impulse and Vitiation-Heated Facilities," Journal of Propulsion and Power, Vol. 16, No. 4, 2000, pp. 709-717. doi: $10.2514 / 2.5631$

[12] Gruber, M.R., Hagenmaier, M.A., and Mathur, T., "Simulating Inlet Distortion Effects in a DirectConnect Scramjet Combustor,” AIAA Paper 06-4680, 2006.

[13] Goyne, C. P., McDaniel, J. C., Krauss, R. H., and Whitehurst, W. B., "Test Gas Vitiation Effects in a Dual-Mode Scramjet Combustor," Journal of Propulsion and Power, Vol. 23, No. 3, 2007, pp. 559-565. doi:10.2514/1.24663

[14] Haw, W. L., Goyne, C. P., Rockwell, R. D., Krauss, R. H., and McDaniel, J. C., "Experimental Study of Vitiation Effects on Scramjet Mode Transition," Journal of Propulsion and Power, Vol. 27, No. 2, 2011, pp. 506-508.

doi: $10.2514 / 1.49090$

Approved for public release; distribution is unlimited. AEDC2013-133. 
[15] Le, D. B., Goyne, C. P., Krauss, R. H., and McDaniel, J. C., "Experimental Study of a Dual-Mode Scramjet Isolator," Journal of Propulsion and Power, Vol. 24, No. 5, 2008, pp. 1035-1041. doi:10.2514/1.32592

[16] Rockwell, R. D., Goyne, C. P., Haw, W., Krauss, R. H., and McDaniel, J. C., "Experimental Study of Test-Medium Vitiation Effects on Dual-Mode Scramjet Performance," Journal of Propulsion and Power, Vol. 27, No. 5, September 2011, pp. 1135-1142. doi: $10.2514 / 1 . B 34180$

[17] Goyne, C. P., Rockwell, R. D., Untaroiu, A., Smayda, M. G., Sklar, A., and Cresci, D., "Dual-Mode Flowpath Design for the SDPTE (Hy-V) Program," JANNAF 43td CS $/ 31^{\text {st }}$ APS $/ 25^{\text {th }}$ PSHS Joint Meeting, JANNAF Paper 785, December 2009.

[18] Smayda et al. "Freejet Testing of a Dual-Mode Scramjet Combustor in an Impulse Facility," Pending publication

[19] Jacobs, P. A., Rogers, R. C., Weidner, E. H., and Bittner, R. D., "Flow Establishment in a Generic Scramjet Combustor," NASA ICASE Report 90-77, October 1990.

[20] Holden, M.S. (1971) "Establishment time of laminar separated flows," AIAA Journal, Vol. 9, No. 11, 1971, pp. 2296-2298.

doi: $10.2514 / 3.6512$

[21] DePiro, M. J., “Design: Scramjet Ground Experiment," Master Thesis, Department of Mechanical and Aerospace Engineering, University of Virginia, Charlottesville, VA, December 2010

[22] Billig, F. S., "Research on supersonic combustion", Journal of Propulsion and Power, Vol. 9, No. 4, July 1993, pp. 499-514.

doi: $10.2514 / 3.23652$

[23] Masatoshi, K., Sadatake, T., "Mach 6 test of a scramjet engine with boundary-layer bleeding and twostaged fuel injection," 12th AIAA International Space Planes and Hypersonic Systems and Technologies, Norfolk, VA, AIAA, 2003.

[24] Waltrup, P.J., and Billig, F.S., "Prediction of Precombustion Wall Pressure Distributions in Scramjet Engines," Journal of Spacecraft and Rockets, Vol. 10, No. 9, 1973

[25] Pulsonetti, M.V., and Stalker, R., “A Study of Scramjet Scaling,” AIAA Paper 96-4533, November 1996 doi: $10.2514 / 6.1996-4533$

[26] Gupte, A. A., Engblom, W. A., Goyne, C. P., and Rockwell, R. D., "Effect of Thermally Induced Deformation in UVa Supersonic Combustion Facility," 49th AIAA Aerospace Sciences Meeting including the New Horizons Forum and Aerospace Exposition, Orlando, FL, AIAA Paper 11-503, January 2011 


\begin{tabular}{|l|l|}
\hline Technical Release: & DATE: \\
004563 & $09 / 11 / 13$ \\
\hline
\end{tabular}

Distribution Statement ---- Approved for public release, distribution unlimited.

Description ---- HSST: Thomas Steva Thesis and Presentation

AEDC Log Number --- 00-

AEDC PA Number --.- AEDC2013-133

Date Approved --- 09/17/13

AEDC Author(s) --- BANCROFT-SA

Outside Author(s) --- Thomas Steva

AF PM Signature --- BANCROFT-SA

Technical Management Review

Comments ---- University of Virginia Thesis and presentation on HSST SDPTE project have been reviewed by HSST PMO and do not include any Distribution C or ITAR information

Export Determining Official Signature ---- SNIPES-MS

Comments --- The Thesis paper and presentation titled, Comparison of a DirectConnect and Free-jet Dual-Mode Scramjet, are a compilation of fundamental research in science and engineering about a military topic that is rapidly moving toward sensitive classification and ITAR Restriction. Based on the research objectives explored and the resulting information documented herein, recommend no export control or specific restrictions on access and dissemination at this time. However, the funding organization for this program, Test Resource Management Center, should be consulted for final approval to publish at the Distribution A level.

Tech Editing Signature ---- STOVALL-KT

Comments --- No tech editing required. Added distribution stmt to footer in both files that author provided in matrix.

STINFO PA Required Signature --- STEWART-JR

Comments ---

Public Affairs Approved Signature ---- WALTON-ML

Comments --- 